\title{
Electroanalysis of Trace Inorganic Arsenic with Gold Nanoelectrode Ensembles
}

\author{
A. Mardegan, ${ }^{\mathrm{a}, \mathrm{b}}$ P. Scopece, ${ }^{* \mathrm{~b}}$ F. Lamberti, ${ }^{\mathrm{c}}$ M. Meneghetti, ${ }^{\mathrm{c}}$ L. M. Moretto, ${ }^{\mathrm{a}}$ P. Ugo ${ }^{* \mathrm{a}}$ \\ a Department of Molecular Sciences and Nanosystems, University Ca' Foscari of Venice, S. Marta 2137, Venice, Italy \\ b CIVEN, Via delle Industrie 5, 30175,Venezia-Marghera, Italy \\ c Department of Chemical Science, University of Padua, via Marzolo 1, 35131 Padova, Italy \\ *e-mail: ugo@unive.it; scopece@civen.org
}

Received: September 30, 2011

Accepted: December 14, 2011

\begin{abstract}
The results of a study on the determination of trace levels of arsenic with nanoelectrode ensembles (NEEs) are reported. In order to lower the detection limit and to increase the number of performable analysis for each NEE, the right choice of the supporting electrolyte concentration and electroanalytical parameters were optimized. The electrochemical behavior of As(III) at NEEs was studied at first by cyclic voltammetry, while trace concentrations of As(III) were determined by anodic stripping square wave voltammetry. The method is characterized by a detection limit as low as $5 \mathrm{ng} / \mathrm{L}(65 \mathrm{pM})$ after 3 min preconcentration at $-0.4 \mathrm{~V}$. Finally, NEEs were applied to trace As analysis in real samples such as certified seawater samples.
\end{abstract}

Keywords: Arsenic, Nanoelectrode ensemble, Anodic stripping voltammetry, Water analysis

DOI: 10.1002/elan.201100555

\section{Introduction}

The control of arsenic concentration in drinking water is an actual challenge because of the toxicity of this element and its widespread presence in the environment [1].

The origin of this presence can be found both in the natural composition of rocks and soils (As is the $20^{\text {th }}$ element in the earth's crust in abundance), and as a consequence of human activity.

In 1993, the World Health Organization (WHO) set to $10 \mu \mathrm{g} / \mathrm{L}$ the maximum limit for As concentration in drinking water, value adopted also by the European legislation. As a consequence, there is a real need for simple and reliable analytical methods able to reach this low detection limit, being, at the same time, suitable for decentralized analysis even in remote areas.

Hydride generation followed by atomic absorption spectroscopy is, perhaps, the most widely used method for inorganic arsenic detection, after Holak's [2] first report in 1969. Considering that As can be present both in the $3+$ and $5+$ oxidation state, a preliminary reduction step is required since only $\mathrm{As}(\mathrm{III})$ reacts with $\mathrm{NaBH}_{4}$ [3].

Inductively coupled plasma (ICP) techniques are also used as analytical tools for arsenic analysis [4]. The most important advantage (but also limit [5]) of this technique is that the high temperature of the plasma atomizes and ionizes all forms of arsenic so that the response does not depend on the molecular speciation of As in the sample. Another possible drawback of ICP-MS is the possible interference from high levels of chloride which generates argon chloride $\left({ }^{40} \mathrm{Ar}{ }^{35} \mathrm{Cl}\right)$ in the plasma which interferes with $\left({ }^{75} \mathrm{As}\right)[6]$.

Among the others, electrochemical methods of analysis are employed for As determination with the advantage of requiring less expensive instrumentation and being suitable for on-site control and decentralized monitoring.

Both cathodic and anodic stripping voltammetry are used for the electrochemical determination of trace As using the hanging mercury electrode [7-9], or gold electrodes [10] as the working electrode.

Recent papers [11,12] showed that the stripping voltammetric (ASV) determination of arsenic can be improved by nanostructuring the electrode surface. In particular, several papers described the successful use of carbon electrodes modified with gold nanoparticles (AuNps) for trace arsenic analysis. The Au-Nps can be deposited by mean of electroless [13] or electrochemical methods $[14,15]$. The so prepared modified electrodes showed detection limit $(D L)$ of $0.01 \mu \mathrm{g} \mathrm{L}^{-1}$ [11]. Trace As(III) has been successfully detected also using gold microelectrode array in which the electrode surface is coated by a thin Nafion film [12].

Arsenic toxicity is function of its speciation; as far as the oxidation state is concerned, it is known that $\mathrm{As}(\mathrm{V})$ is 100 times less toxic than As(III) [16]. Therefore, a method to differentiate between these two redox states is required. Different approaches to As redox speciation have been described after the first attempt performed by Nurnberg [17]. In most cases, the speciation analysis is performed by quantifying the difference between As(III), 
originally present in the sample, and total inorganic arsenic determined after reduction of $\mathrm{As}(\mathrm{V})$ to $\mathrm{As}(\mathrm{III})$. The latter process can be performed by using chemical or electrochemical reduction [18], but the former method is the most widely applied. For this purpose, various chemical reducing agents have been used such as potassium iodide and ascorbic acid [19], sodium sulfite [20], gaseous $\mathrm{SO}_{2}$ [17], cuprous chloride [21,22] and $\alpha$-cysteine [10,23]. However, some of them are not suitable for combination with $\mathrm{ASV}(\mathrm{KI})$ or require complex setup $\left(\mathrm{SO}_{2}\right.$ and $\left.\mathrm{Cu}_{2} \mathrm{Cl}_{2}\right)$.

In the present work we choose to use solid $\alpha$-cysteine as the reducing agent, which acts easily and efficiently on $\mathrm{As}(\mathrm{V})$ reduction, according to the reaction shown in Scheme 1:

In order to try to further improve the reliability and analytical performances of the ASV determination of trace arsenic, in the present work we examine the possibility to exploit the improved electroanalytical performances of the so called nanoelectrode ensembles (NEEs). It was indeed demonstrated that, thanks to dramatically improved signal to background current ratio and enhanced diffusion $[24,25]$, NEEs can be successfully applied to trace analysis of a variety of redox analytes ranging from small organics $[26,27]$ to large redox proteins and antigens $[28,29]$, from antibiotics [30] to iodide [31,32].

In the present work we examine the use of NEEs for the anodic stripping analysis of inorganic arsenic focusing, in particular, on the optimization of the analytical conditions in order to lower the $D L$ and improve the analytical performance. Note that, up to know, NEEs were used for the direct determination of analytes and this is the first paper showing that such nanostructured electrodes can be applied to ASV analysis. With respect to the so-called GNEEs grown from seeded Au-Nps in thiol functionalized silicate network [33], the membrane template NEEs used here allow a better control of the nanoelectrode density. The improved ratio between the active and geometric area of the NEEs used here with respect to the GNEE in ref [33], should improve the signal/background current ratio, further lowering detection limits [25,34].

\section{Experimental}

\subsection{Materials}

Polycarbonate filtration membranes (SPI-Pore, $47 \mathrm{~mm}$ filter diameter, $6 \mu \mathrm{m}$ filter thickness, $6 \times 10^{8}$ pores $\left./ \mathrm{cm}^{2}\right)$ with a nominal pore diameter of $30 \mathrm{~nm}$ and coated with the wetting agent polyvinylpyrrolidone were used as the templates to prepare the NEEs.

As(III) stock solutions $(100 \mathrm{mg} / \mathrm{L})$ were prepared by dilution of a $0.05 \mathrm{~mol} / \mathrm{L}$ standard $\mathrm{NaAsO}_{2}$ solution (Carlo Erba). As(V) stock solutions $(1000 \mathrm{mg} / \mathrm{L})$ were prepared from a $1000 \mathrm{mg} / \mathrm{L}$ standard commercial solution of $\mathrm{As}_{2} \mathrm{O}_{5}$ (tritisol, Merck). All other solutions were prepared with ACS grade reagents. Purified water (18.3 M $\Omega$ ) was obtained using a Human UP 900 water purification system.

CASS- 4 certified reference standard was provided by the Canadian National Research Council. It consists of sea water (Nearshore seawater), acidified with $\mathrm{HNO}_{3}$, with mass fractions and mass concentrations assigned for 12 elements. The certified concentration of As is $1.11 \pm$ $0.16 \mu \mathrm{g} / \mathrm{L}$ and of $\mathrm{Cu}$ is $0.592 \pm 0.055 \mu \mathrm{g} / \mathrm{L}$.

\subsection{Apparatus}

All electroanalytical measurements were carried out at room temperature $\left(22 \pm 1^{\circ} \mathrm{C}\right)$ using a three-electrodes single compartment cell equipped with a platinum wire counter electrode and an $\mathrm{Ag} / \mathrm{AgCl}$ ( $\mathrm{KCl}$ saturated) reference electrode. All potential values are referred to this reference electrode.

A CHI440 apparatus controlled via PC by its own software, was used for voltammetric measurements.

\subsection{Electrodes Preparation}

The nanoelectrode ensembles were prepared using the electroless plating procedure and assembled using a previously described procedure [25] and following modifications [35-37].

Briefly, after wetting for $2 \mathrm{~h}$ in methanol, the tracketched polycarbonate membrane was sensitized into $0.026 \mathrm{M} \mathrm{SnCl}_{2}, 0.07 \mathrm{M}$ trifluoroacetic acid in $50 \%$ methanol in water, for $45 \mathrm{~min}$. After rinsing in methanol, the membrane was dipped in $0.029 \mathrm{M} \mathrm{Ag}\left[\left(\mathrm{NH}_{3}\right)_{2}\right] \mathrm{NO}_{3}$ for $10 \mathrm{~min}$. The membrane was rinsed in methanol and then in water and successively was immersed into the Au plating bath containing $7.9 \times 10^{-3} \mathrm{M} \mathrm{Na}_{3} \mathrm{Au}\left(\mathrm{SO}_{3}\right)_{2}$ in $0.127 \mathrm{M}$ $\mathrm{Na}_{2} \mathrm{SO}_{3}$, at $0^{\circ}$. After $30 \mathrm{~min}, 0.625 \mathrm{M}$ formaldehyde was added to the bath. Electroless deposition was allowed to proceed for $15 \mathrm{~h}$, after which additional $0.625 \mathrm{M}$ formaldehyde was added.

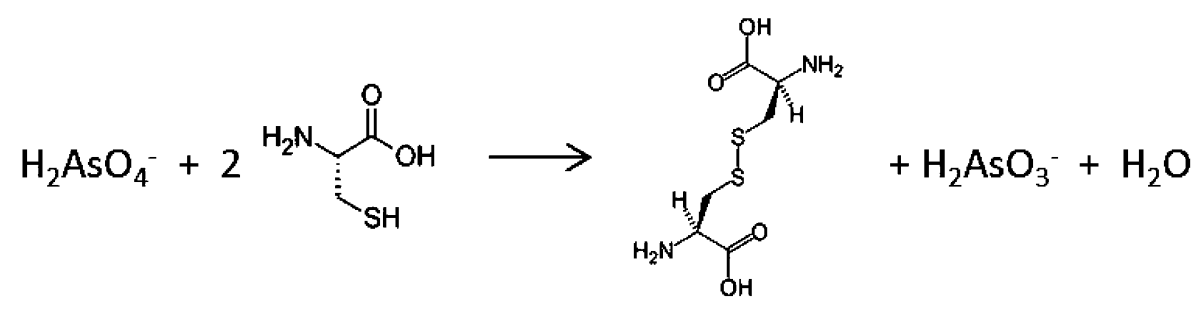

Scheme 1. As(V) reduction scheme. 
After a total of $24 \mathrm{~h}$ of plating, the golden membrane was rinsed with water and dipped for $6 \mathrm{~h}$ in $10 \% \mathrm{HNO}_{3}$, then rinsed again with water and dried. Handy NEEs were assembled as previously described [25].

A small piece (approximately $8 \mathrm{~mm} \times 8 \mathrm{~mm}$ ) of golden membrane was attached to a suitable conductive substrate; the gold layer on the outer face of the membrane was removed by peeling with scotch tape (so that only the head of the gold nanowires inside the pores will be exposed to the sample solution); all the surface of the NEE, apart a hole of $3 \mathrm{~mm}$ diameter (which defines the geometric area of the ensemble, $A_{\text {geom }}=0.07 \mathrm{~cm}^{2}$ ), was insulated with a film of plastics (Monokote by Topflite). The estimated active area $\left(A_{\text {act }}\right)$, i.e. the area of the $\mathrm{Au}$ nanodisks exposed is $3 \times 10^{-4} \mathrm{~cm}^{2}$ [37]. Good sealing between the nanoelectrodes and the polycarbonate was assured by heating the $\mathrm{NEE}$ at $150^{\circ} \mathrm{C}$ for $15 \mathrm{~min}$.

Conventional "macro" gold electrodes, hereafter named " $A u_{\text {macro }}$ ", were prepared via sputtering deposition (roughness $R_{\mathrm{a}}=15 \mathrm{~nm}$ ) into a spirally tracked polycarbonate (PC) slide (a support for CDs). This kind of material allows the deposition of gold without any interlayer and therefore the preparation of the electrode became easier. The gilded plate was cut into slides (ca. $2.5 \mathrm{~cm} \times 1.0 \mathrm{~cm})$ and the geometric area of the electrodes $\left(0.07 \mathrm{~cm}^{2}\right)$ was defined, as for the NEE, by the diameter of a hole punched in a strip of insulating tape. The electri-
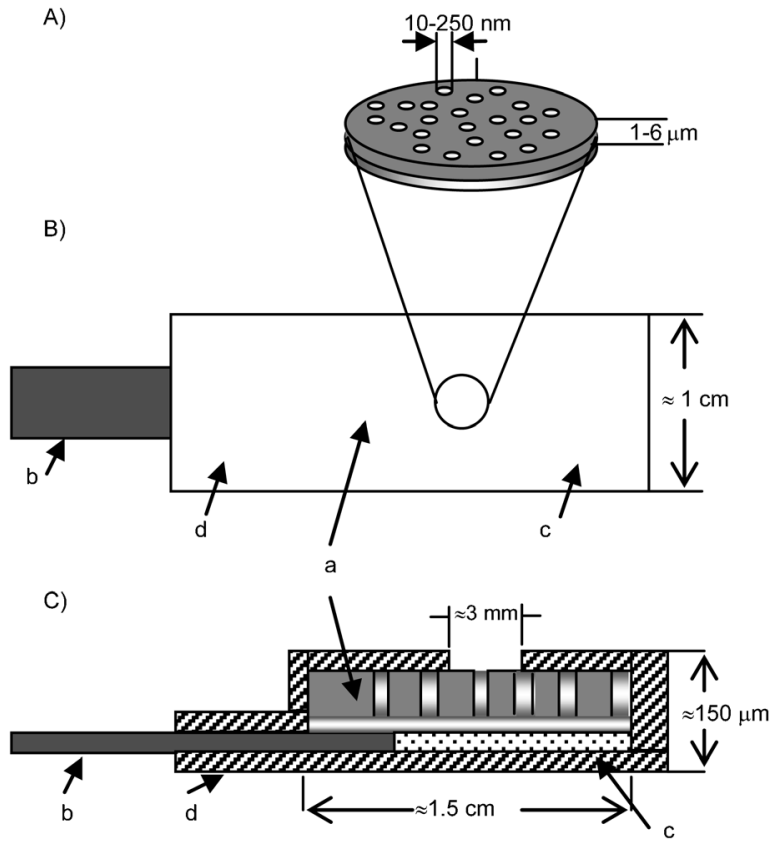

Fig. 1. Scheme of a Au-NEE prepared using a track-etched polycarbonate membrane as template (A). Particular of the section of the active area; (B) top view, (C) section of the all NEE ready for use as working electrode. a) Track-etched golden membrane; b) copper adhesive tape with conductive glue to connect to instrumentation; c) aluminum adhesive foil with non-conductive glue; d) insulating tape. Not all details (namely, the nanoelectrodes dimension) are in scale. cal contact was made with a copper tape before placing the insulating tape.

\subsection{Procedures}

\subsubsection{Determination of As(III)}

$0.33 \mathrm{~mL}$ of $6 \mathrm{M} \mathrm{HCl}+65 \mathrm{mg}$ hydrazine dihydrochloride were added to $10 \mathrm{~mL}$ of water (or to $10 \mathrm{~mL}$ of diluted certified reference solution). ASV measurements were performed as follows: i) accumulation at $-0.4 \mathrm{~V}$ performed for the desired time under continuous stirring; ii) $15 \mathrm{~s}$ equilibration in quiet solution; iii) SWV stripping from -0.4 to $0.45 \mathrm{~V}$ at $250 \mathrm{~Hz}$ frequency, square wave amplitude $75 \mathrm{mV}$, scan increment $12 \mathrm{mV}$.

\subsubsection{Determination of $A s(V)$}

$50 \mathrm{~mL}$ of $\mathrm{As}(\mathrm{V})$ solution, $314 \mu \mathrm{L}$ of $0.78 \mathrm{M}$ hydrazine (final concentration $1.9 \mathrm{mM}$ ) and $30 \mathrm{mg}$ of solid cysteine $(4.9 \mathrm{mM})$ were heated at $80^{\circ}$ in a water bath for $30 \mathrm{~min}$ under continuous stirring. After cooling to room temperature the solution was brought to $50 \mathrm{~mL}$ in a volumetric flask and analyzed with the same procedure used for As(III).

\section{Results and Discussion}

\subsection{Selection of the Electrolyte}

According to previous literature $[18,38]$, at first we examined the electrochemical behavior of NEEs in $1 \mathrm{M} \mathrm{HCl}$, $62 \mathrm{mM}$ hydrazine [18,38-42].

Figure $2 \mathrm{a}$ shows the square wave voltammograms recorded at $\mathrm{NEE}$ in $1 \mathrm{M} \mathrm{HCl}$. One can note that the background current in the blank electrolyte increases in subsequent scans, displaying a drift. At the seventh scan the drift was approximately $500 \mathrm{nA}$. This effect suggests the

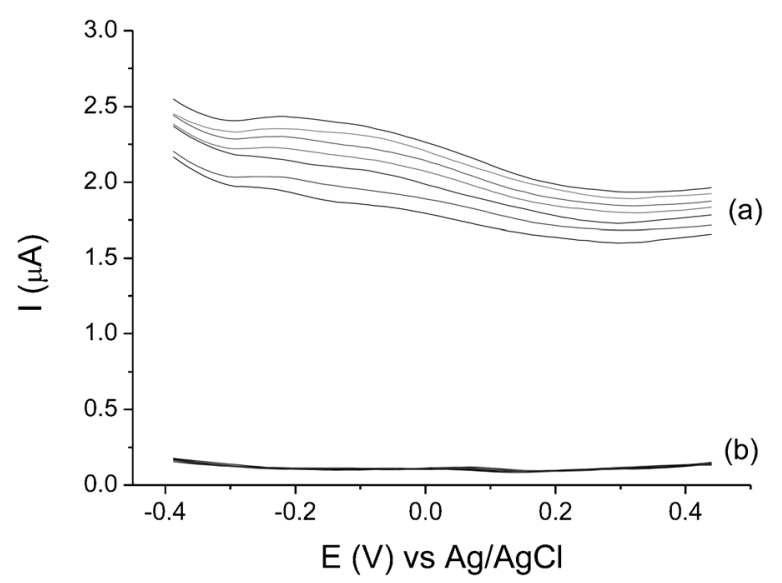

Fig. 2. Square wave voltammograms recorded at NEE in $1 \mathrm{M}$ $\mathrm{HCl}$ (a) or $0.2 \mathrm{M} \mathrm{HCl}$ (b) and $62 \mathrm{mM}$ hydrazine. SW parameters: scan increment $12 \mathrm{mV}$; amplitude $75 \mathrm{mV}$; frequency $250 \mathrm{~Hz}$; initial potential $-0.4 \mathrm{~V}$. 
deterioration of the NEE surface with progressive exposure of the gold of the nanofibers and consequent increase of the double-layer charging current [43].

In order to investigate such a possibility, the AFM characterization before and after the exposure of the NEEs to $1 \mathrm{M} \mathrm{HCl}$ was performed. It was recently shown that AFM can furnish useful information on the morphology of NEEs [37]. Note that, in the present case, we are interested more in the general behavior of all the assembly rather than on the destiny of the individual nanoelectrodes. Therefore, the AFM scans were performed on a relatively large spatial scale, examining areas $50 \times 50 \mu \mathrm{m}$ wide. At variance with the previous paper [37], working
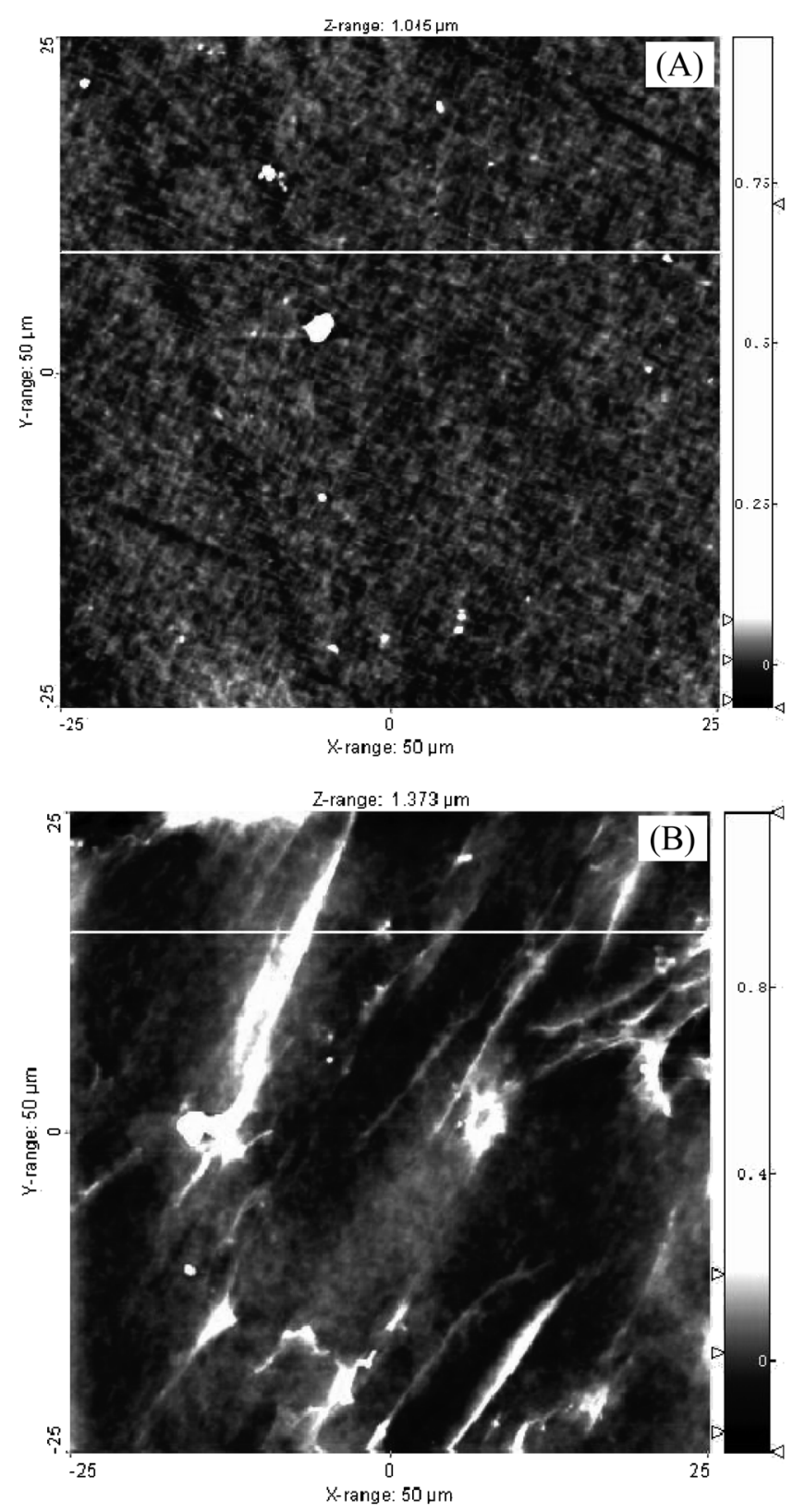

Fig. 3. AFM topographic images of the surface: (A) of brand new NEE, (B) a NEE after use in $1 \mathrm{M} \mathrm{HCl}$. with such a wide spatial scale, the single nanoelectrodes are only scarcely distinguished from the surrounding polycarbonate. Relevant AFM topographies are shown in Figure 3, where Figure $3 \mathrm{~A}$ refers to a brand new NEE and Figure 3B shows the topography of a NEE after being used in $1 \mathrm{M} \mathrm{HCl}$.

One can note that the brand new NEE presents a low surface roughness, which is quite homogeneously distributed all over the examined area. On the contrary, the NEE used in $1 \mathrm{M} \mathrm{HCl}$ shows a much rougher surface, with deep "canyons and valleys" running diagonally all through the surface. Figure 4 shows relevant profilometric patterns run in correspondence of the white lines in Figure $4 \mathrm{~A}$ and $4 \mathrm{~B}$ and for a NEE after use in $0.2 \mathrm{M} \mathrm{HCl}$ (see below). The comparison between the broken line (brand new NEE) and gray line (1 M HCl treated NEE) profiles confirms the dramatic increase in roughness caused by the $1 \mathrm{M} \mathrm{HCl}$ electrolyte. These evidences suggest that in $1 \mathrm{M} \mathrm{HCl}$ the surface of the PC is partially etched, probably because of hydrolysis of the polymer by the concentrated acid.

This behavior suggested us to test the effect of a decrease of the $\mathrm{HCl}$ concentration to $0.2 \mathrm{M}$ (always keeping hydrazine to $62 \mathrm{mM}$ ). Figure $2 \mathrm{~b}$ shows an overlay of ten voltammograms recorded in this medium and demonstrates that now the background current values stay rather constant for many consecutive scans, moreover the average SWV background current is much lower, setting around a value of $0.1 \mu \mathrm{A}$.

The comparison of the AFM profilometric sections recorded for the NEE after use in $0.2 \mathrm{M} \mathrm{HCl}$ (Figure 4, black line) indicates that the more diluted acid doesn't damage the NEE surface. Diluted $\mathrm{HCl}$ (with hydrazine) could potentially be the electrolyte of choice. To test such possibility, in the following section we will examine the cyclic voltammetric behavior of As(III) at NEEs in such a medium.

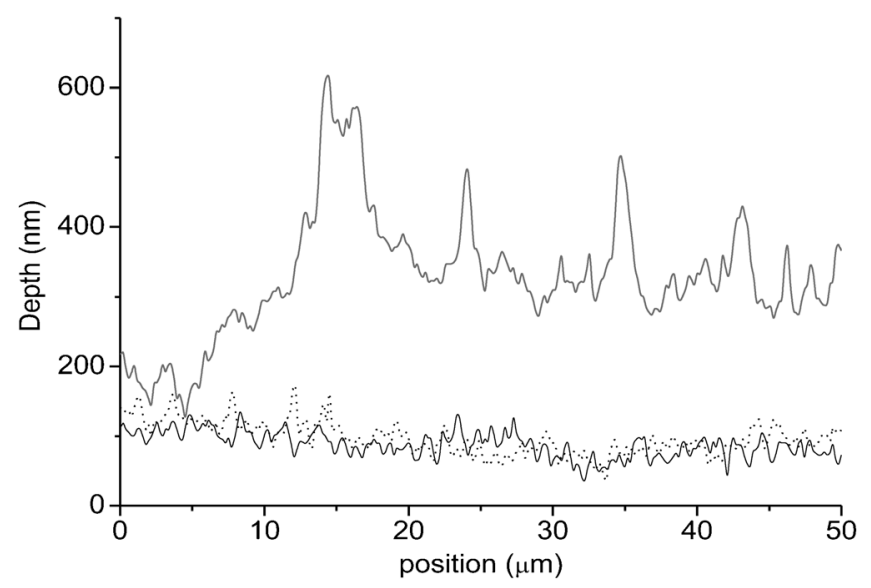

Fig. 4. Profilometric patterns recorded for a brand new NEE (dotted black line), for a NEE used in $0.2 \mathrm{M} \mathrm{HCl}$ (full black line) and of a NEE used in $1 \mathrm{M} \mathrm{HCl}$ (full grey line). 


\subsection{CV of As(III) at NEE}

Figure 5A shows the CVs recorded at $200 \mathrm{mV} / \mathrm{s}$ in $40 \mathrm{mg} /$ L As(III) (in $0.2 \mathrm{M} \mathrm{HCl}, 62 \mathrm{mM}$ hydrazine, full line) vs. the background signal recorded in aerated pure supporting electrolyte (dotted line). The forward scan of the CV recorded in the presence of $\mathrm{As}(\mathrm{III})$, is characterized by a cathodic peak at $-0.400 \mathrm{~V}$. CVs recorded at different scan rates (not shown) indicate that the potential of the cathodic peak shifts from $-0.350 \mathrm{~V}$ (at $50 \mathrm{mV} / \mathrm{s}$ ) to $-0.450 \mathrm{~V}$ (at $500 \mathrm{mV} / \mathrm{s})$. The peak current scales linearly with $v^{1 / 2}$ (see Figure 5A, Inset), indicating a diffusion controlled process. In the backward scan an anodic peak is detected at about $0.220 \mathrm{~V}$, whose peak height scales linearly with the scan rate (not shown). Note that in the reoxidation scan a crossover in the voltammogram is observed, indicating a process involving the deposition of a metal on electrodes having a different chemical nature from the deposit itself $[44,45]$.

All these evidences agree with the reduction of dissolved As(III) in the forward scan, according to:

$$
\operatorname{As}(\mathrm{III})+3 \mathrm{e}^{-} \rightarrow \operatorname{As}(0)
$$

The quite large value of $E_{\mathrm{p}}-E_{\mathrm{p} / 2}$, which is $100 \mathrm{mV}$ at $v=200 \mathrm{mV} / \mathrm{s}$, indicates that the reduction is not fully re-
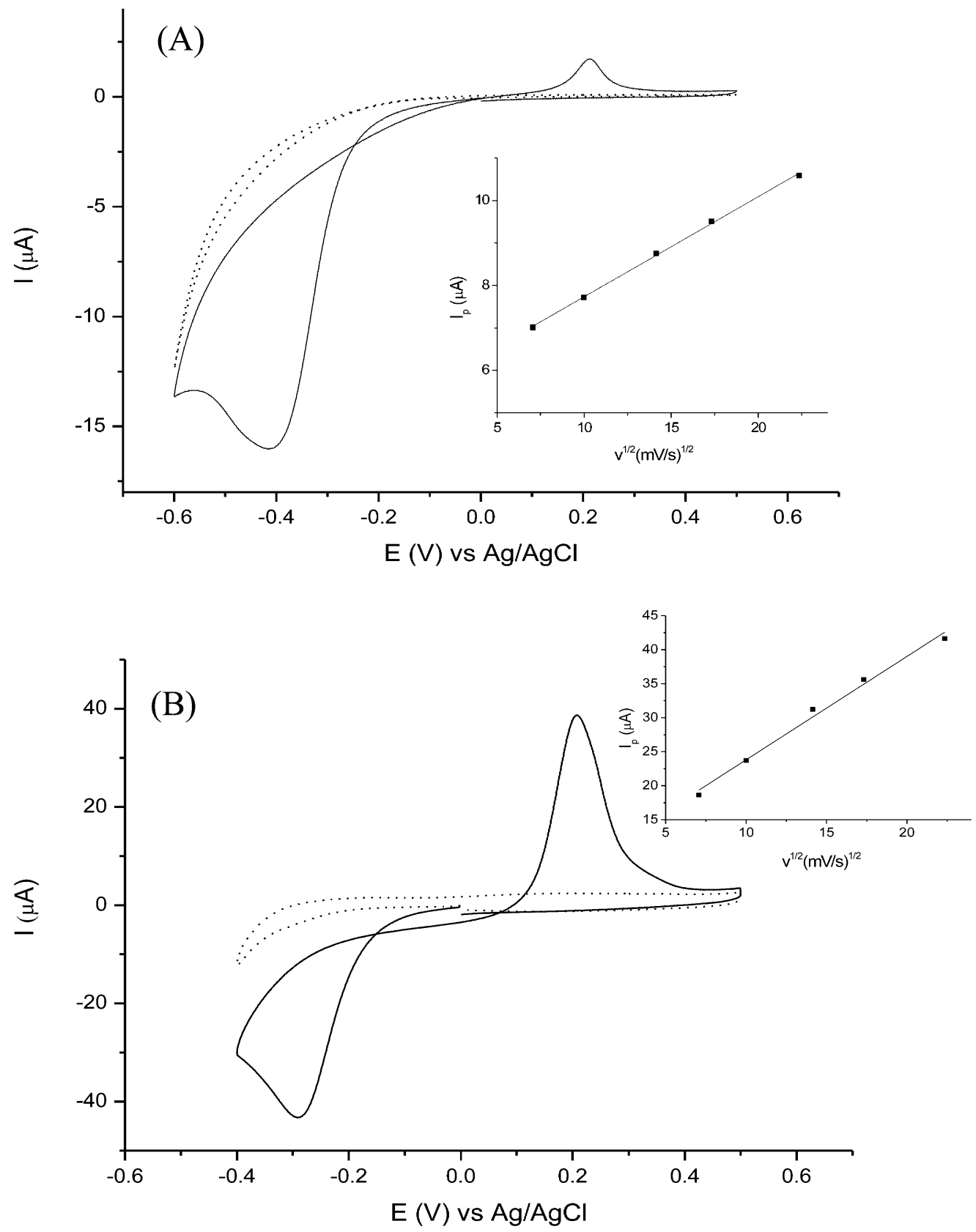

Fig. 5. Cyclic voltammograms recorded at $0.2 \mathrm{~V} / \mathrm{s}$ at a NEE (A) and at an $\mathrm{Au}_{\text {macro }}$ electrode (B) in solution of $40 \mathrm{mg} / \mathrm{L} \mathrm{As}(\mathrm{III})$ in $\mathrm{HCl} 0.2 \mathrm{M}, 62 \mathrm{mM}$ hydrazine. Forward scan: cathodic. Insets: dependence of $i_{\mathrm{p}}$ cathodic on the square root of the scan rate. 
versible. In the backward scan the reverse reaction occurs which corresponds to the anodic stripping of deposited $\operatorname{As}(0)$.

Figure $5 \mathrm{~B}$ shows the $\mathrm{CV}$ recorded in the same solution than in Figure $5 \mathrm{~A}$, but at a $\mathrm{Au}_{\text {macro }}$ electrode. In this case, the reduction process takes place at less negative potential values (approximately at $-0.245 \mathrm{~V}$ ) than at the NEE, with the peak current still linearly dependent on $v^{1 / 2}$ (see Figure 5B, Inset). The oxidation peak current recorded is much higher than at the NEE, but still depends linearly on $\mathrm{v}$. This behavior indicates that the electrochemical process occurring at the NEE and the $\mathrm{Au}_{\text {macro }}$ is the same.

The large cathodic shift in the peak potential relevant to As (III) reduction at the NEE with respect to the $\mathrm{Au}_{\text {macro, }}$ agrees with a slow electron transfer kinetics. It is indeed known that NEEs behave like electrodes with partially blocked surface $[25,26]$, therefore they are more sensitive to electron transfer kinetics than electrodes with continuous surface, this reflecting in an increase in the electrochemical overpotential which influences the electrochemical behavior for redox couples with slow electron transfer kinetics. For a reduction process this reflects in a cathodic shift of the peak potential as observed by us for arsenic.

Also the lower current for the $\operatorname{As}(0)$ stripping peak at the NEE vs. the $\mathrm{Au}_{\text {macro }}$ agrees with the microscopic morphology of the NEE. Since the gold active area is much smaller at the NEE, a lower amount of elemental arsenic can be deposited and, consequently, a much lower reoxidation stripping peak is recorded. Note that at the stripping peak a surface controlled process occurs $\left(i_{\mathrm{p}}\right.$ proportional to $v$ ), while the reduction process is diffusion controlled $\left(i_{\mathrm{p}}\right.$ proportional to $\left.v^{1 / 2}\right)$ and that at NEEs, even under total overlap diffusion conditions, diffusional fluxes at the nanoelectrodes are dramatically enhanced [25].
Such a different dependence on mass fluxes can explain the large difference in peak current observed at the NEE for the reduction versus reoxidation process.

\subsection{AS-SWV of As(III) at NEE}

For the determination of trace level of arsenic, we chose to operate with NEE using anodic stripping-square wave voltammetry, AS-SWV. Preliminary experiments indicated that a deposition time between $120 \mathrm{~s}$ and $180 \mathrm{~s}$ gives good results, the final choice depending on the concentration of the analyte. At longer deposition times we observed a decrease in the reproducibility of the stripping peak current and shorter linear range (see below). This fact is explained taking into account a saturation effect of the available Au surface of the nano-sites of the NEE, in agreement with the above cyclic voltammetric observations.

Figure 6 shows the AS-SWVs recorded at a NEE in $0.2 \mathrm{M} \mathrm{HCl}, 62 \mathrm{mM}$ hydrazine, spiked with increasing amounts of $\mathrm{As}(\mathrm{III})$. A very sharp stripping peak is recorded at $0.0 \mathrm{~V}$, with peak current which scales linearly for concentrations between 0.2 and $3.0 \mu \mathrm{g} / \mathrm{L}$ (see Inset).

The evidence that in Figure 6 the oxidation of As takes place at less positive potential values could be due to the fact that at nanoelectrodes in diluted solutions, only small nuclei of elementary As are formed, whose oxidation is energetically easier than that of a bulk deposit.

As shown in Figure 7 (triangles) the increase of As(III) concentration above $8-10 \mu \mathrm{g} / \mathrm{L}$ causes the progressive lowering of the sensitivity up to a saturation effect.

The effect of decreasing the deposition time to $120 \mathrm{~s}$ is shown in Figure 7 (squares). As expected, the sensitivity at low concentrations decrease, but the linear range increases.

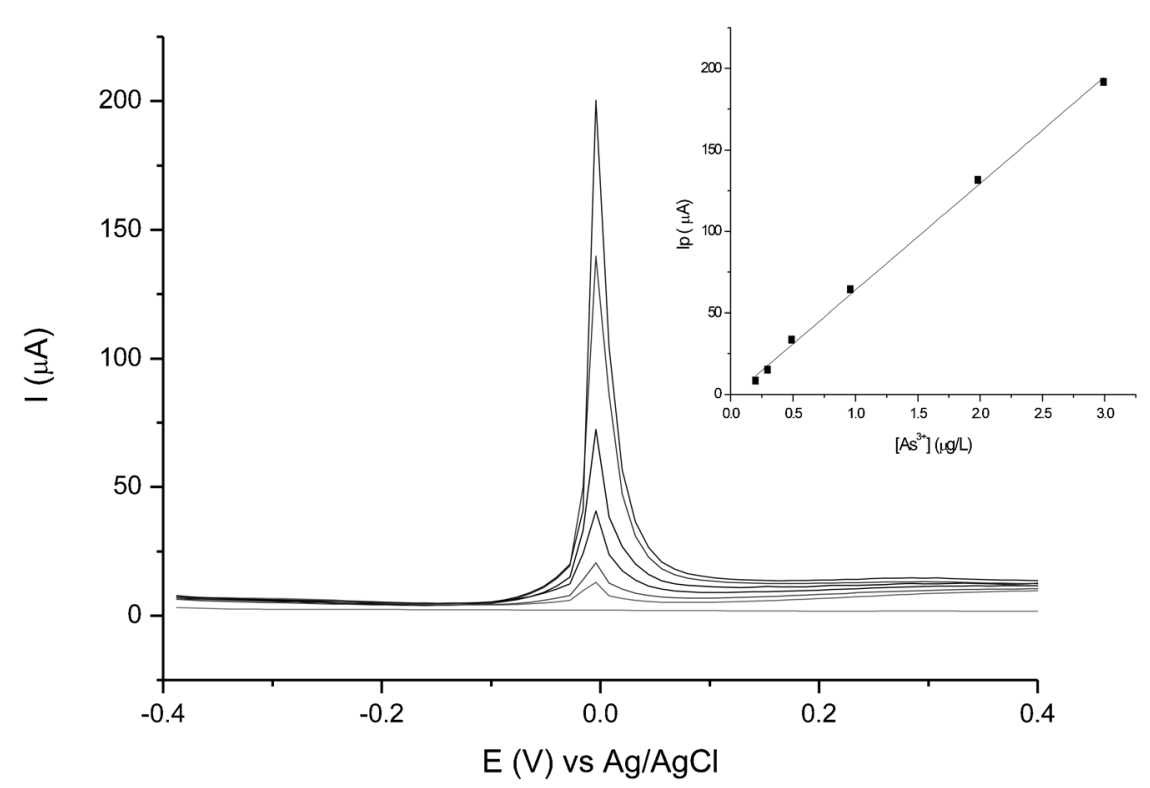

Fig. 6. AS-SWVs at $\mathrm{NEE}$ in $0.2 \mathrm{M} \mathrm{HCl}$ at different $\mathrm{As}(\mathrm{III})$ concentrations (from 0 to $3.0 \mu \mathrm{g} / \mathrm{L}$ ). Inset: Relevant calibration plot. Deposition at $-0.4 \mathrm{~V}$ for $180 \mathrm{~s}$. Other parameters as in Figure 2. 


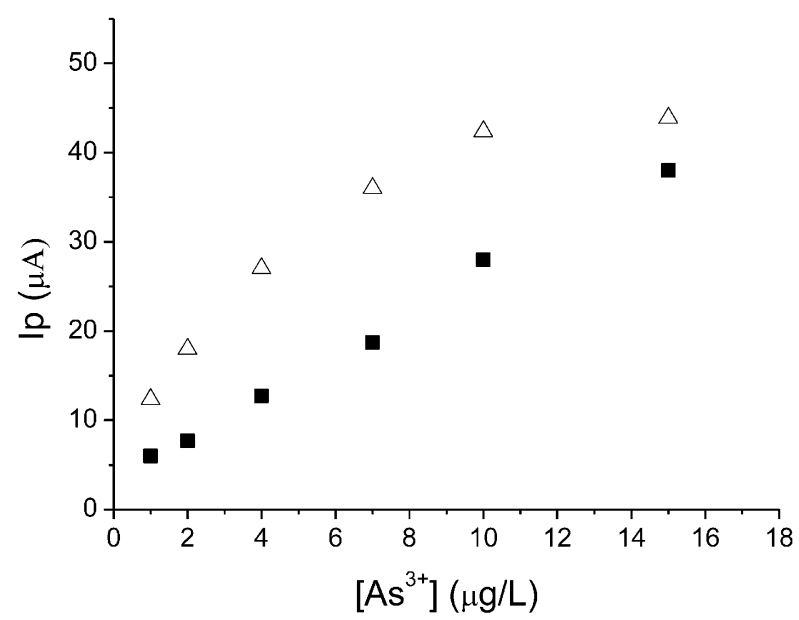

Fig. 7. $I_{\mathrm{p}}$ vs. As(III) plot for continuous additions of As(III) at deposition time of $180 \mathrm{~s}$ (triangles) and $120 \mathrm{~s}$ (squares).

For comparison, Figure 8 shows the AS-SWVs at a $\mathrm{Au}_{\text {macro }}$ electrode recorded at $\mathrm{As}(\mathrm{III})$ concentrations from 20 to $150 \mu \mathrm{g} / \mathrm{L}$, which shows that the stripping peak shifts to slightly more positive potential values, with much larger half-peak width (approximately $120 \mathrm{mV}$ ).

Table 1 compares the analytical parameters obtained with a NEE and a $\mathrm{Au}_{\text {macro }}$. The NEE furnishes a detection

Table 1. Comparison of the AS-SWV performances of NEE and $\mathrm{Au}_{\text {macro }}$ electrode for the $\mathrm{As}$ (III) determination (deposition time $180 \mathrm{~s}) . D L$ : Detection limit calculated as $D L=3 \sigma_{\mathrm{b}} / m$, where $\sigma_{\mathrm{b}}$ is the standard deviation of the blank; $L R=$ Linear range.

\begin{tabular}{lll}
\hline & $\mathrm{NEE}$ & $\mathrm{Au}_{\text {macro }}$ \\
\hline$D L$ & $0.005 \mu \mathrm{g} / \mathrm{L}$ & $0.75 \mu \mathrm{g} / \mathrm{L}$ \\
$L R$ & $0.2-6 \mu \mathrm{g} / \mathrm{L}$ & $20-150 \mu \mathrm{g} / \mathrm{L}$ \\
Sensitivity $(m)$ & $65.57 \mu \mathrm{A} \times \mathrm{L} / \mu \mathrm{g}$ & $5.51 \mu \mathrm{A} \times \mathrm{L} / \mu \mathrm{g}$ \\
$\sigma_{\mathrm{b}}$ & $0.11 \mu \mathrm{A}$ & $1.38 \mu \mathrm{A}$ \\
\hline
\end{tabular}

limit roughly 2 order of magnitude lower, however the linearity range at the NEE is shorter, in agreement with the NEE agrees with the hypothesis of the saturation of the gold nano-sites that occurs for the NEE: the larger is the available gold surface, the wider results the linear range.

In comparison with other nanostructured electrodes, $D L$ at our NEEs compares or is even slightly lower than previous achievements [11-15].

\subsection{Redox State Speciation and Copper Interference}

Preliminary experiments performed with $\mathrm{Au}_{\text {macro }}$ electrode confirmed the completion of the reduction of $\mathrm{As}(\mathrm{V})$ to $\mathrm{As}(\mathrm{III})$ using cysteine as the reducing agent, under the conditions described in the experimental section. It was observed indeed that AS-SWVs performed on equimolar concentration of As(III) generated by in situ chemical reduction of $\mathrm{As}(\mathrm{V})$, and $\mathrm{As}(\mathrm{III})$ added directly as $\mathrm{NaAsO}_{2}$ give exactly the same voltammetric peaks, with calibration plots displaying the same sensitivity. Figure 9 shows the AS-SWVs of As(III) produced by chemical reduction of $\mathrm{As}(\mathrm{V})$ with cysteine, together with the voltammograms recorded after two standard additions of As(III). These signals scale linearly with the total content of As, indicating that the possible presence of a cysteine excess and of generated cystine do not interfere.

Since it is known that copper(II) can interfere with As(III) ASV determination [46], we performed a series of experiments adding increasing concentrations of $\mathrm{Cu}(\mathrm{II})$ to a constant $\mathrm{As}$ (III) concentration (namely $2 \mu \mathrm{g} /$ L). It was observed that the stripping peak current of $\mathrm{As}(\mathrm{III})$ is practically unaffected by the addition up to a 5fold copper excess. Two stripping peaks (not shown) for $\mathrm{Cu}$ are indeed observed at approximately $-0.100 \mathrm{~V}$ vs. $\mathrm{Ag} / \mathrm{AgCl}\left(\mathrm{Cu}(0) \rightarrow \mathrm{Cu}(\mathrm{I})+\mathrm{e}^{-}\right)$and at $+0.350 \mathrm{~V}(\mathrm{Cu}(\mathrm{I}) \rightarrow$ $\left.\mathrm{Cu}(\mathrm{II})+\mathrm{e}^{-}\right)$, but they are separated enough from the As

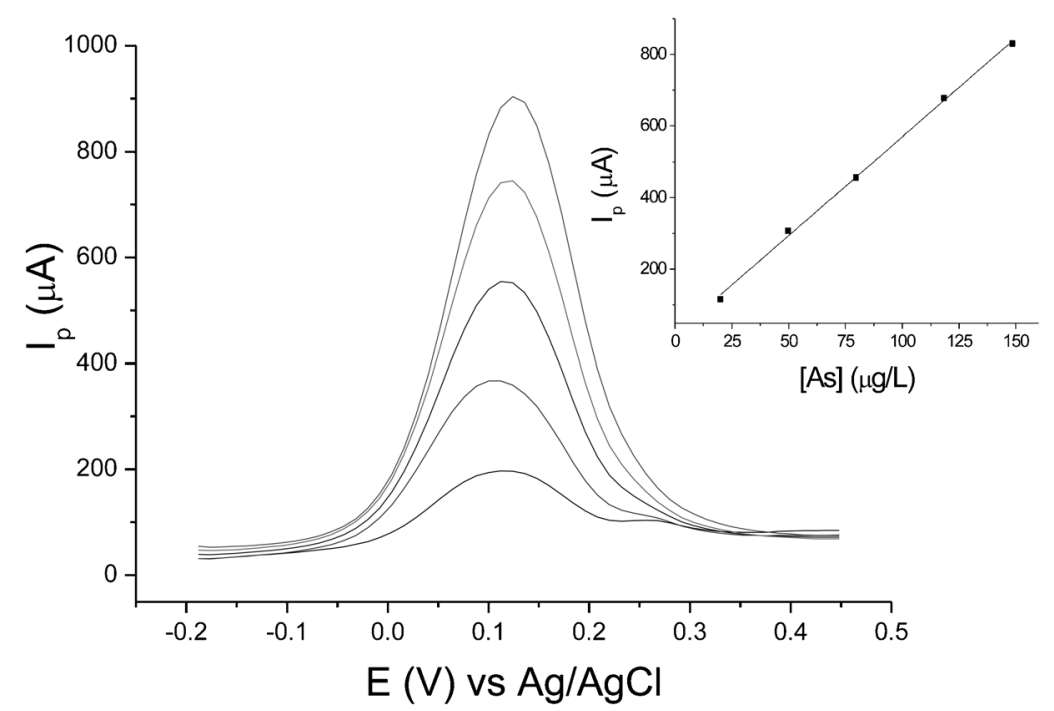

Fig. 8. AS-SWVs recorded at $\mathrm{Au}_{\text {macro }}$ electrode at increasing concentration of $\mathrm{As}(\mathrm{III}): 20,50,75,125$ and $150 \mu \mathrm{g} / \mathrm{L}$. Inset: Relevant calibration plot. Other parameters as in Figure 6. 


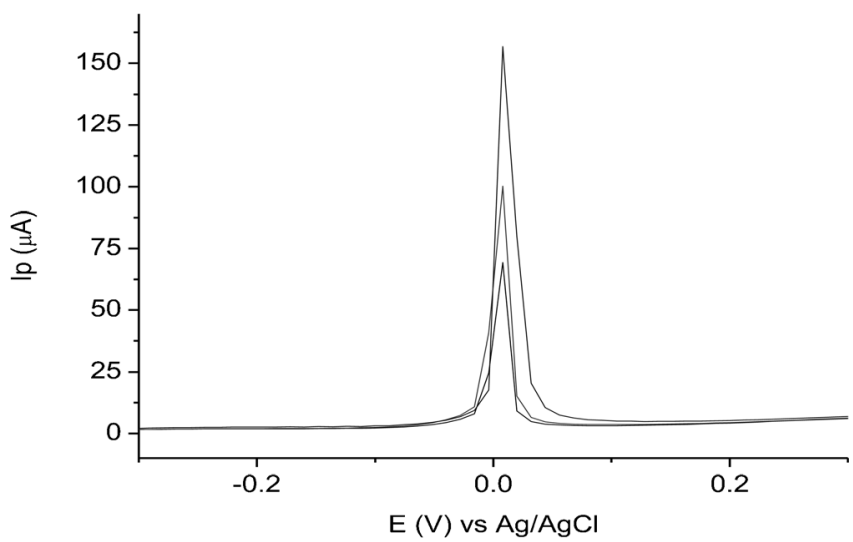

Fig. 9. AS-SWVs recorded at a NEE in $0.2 \mathrm{M} \mathrm{HCl}$ and subsequent additions of As(III) chemically reduced by cysteine $(5,15$ and $30 \mu \mathrm{g} / \mathrm{L})$.

peak to cause only a minor interference ( $\max 4.5 \%$ for the As stripping peak).

\subsection{Preliminary Results in the Electroanalysis of Certified Samples}

The above-developed method was tested for the determination of As in CASS-4.

After reduction with cysteine (see Section 2.4.2), $5 \mathrm{~mL}$ of CASS-4 were diluted 1:1 with $\mathrm{HCl}$ (final concentration $0.2 \mathrm{M}$ ), adding hydrazine dihydrochloride (62 $\mathrm{mM})$.

The AS-SWV is characterized by a peak at $0.0 \mathrm{~V}$ vs. $\mathrm{Ag} / \mathrm{AgCl}$ which increases linearly after standard addition of As(III). The sample concentration, calculated by extrapolation of the calibration plot shown in Figure 10 and considering the dilution factor, was $1.18 \pm 0.06 \mu \mathrm{g} / \mathrm{L}$ (based on three replicates). This value is in satisfactory agreement with the value of $1.11 \pm 0.16 \mu \mathrm{g} / \mathrm{L}$ declared by the National Research Council of Canada.

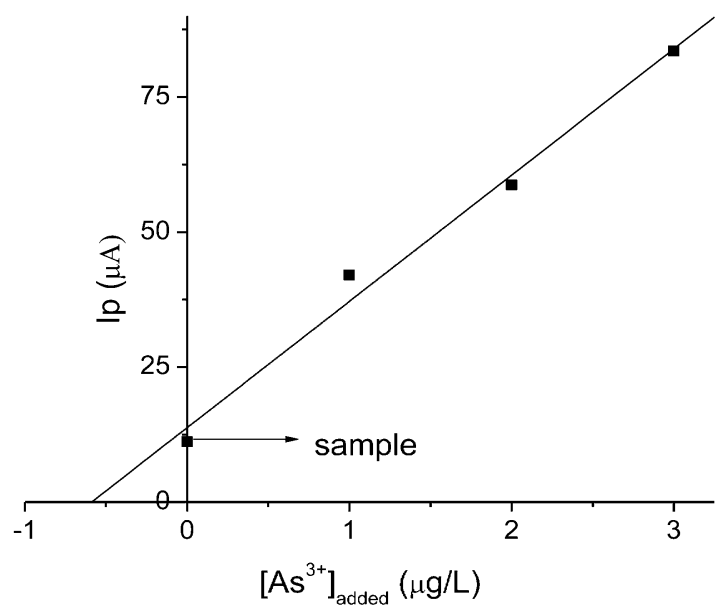

Fig. 10. Standard addition plot obtained by AS-SWV with NEE on a CASS-4 sample diluted $1: 1$.

\section{Conclusions}

In the present work we demonstrate that DLs with NEEs are significantly lower than those achieved with gold macroelectrodes and are competitive with respect to other nanostructured gold electrodes for the determination of inorganic As. With respect to other nanostructured gold electrodes, the surface of the NEEs is more controllable and reproducible, since the geometry of the nanoelectrodes is fully controlled by the geometry of the templating membrane. On the other hand, NEEs present a shorter dynamic range than the Au-macroelectrodes, therefore their use is advised especially for trace and ultratrace determinations, that is for concentrations $<10 \mu \mathrm{g} / \mathrm{L}$. This agrees with the operativity of a surface saturation effect which is enhanced by the very small active area of the NEE.

The choice of the appropriate supporting electrolyte minimizes the damage of the electrode surface and allows one to use an individual NEE for one complete analysis without suffering any deterioration problem. Anyway, considering the low cost of the electrodes (from one membrane of the cost of approximately 2 USD one can prepare $40 \mathrm{NEEs}$ ) their use as disposable electrodes is recommended.

Experiments with NEEs in certified samples showed very good results supporting the practical applicability of these nanostructured electrodes for trace As analysis in natural water.

\section{Acknowledgements}

This work was supported financially by MIUR (Rome Project PRIN2008 MWHCP2) and Regione Veneto (RESMIA Project). We thank Dr. Nicolo Mazzucco for preliminary experimental results and Dr. Piero Schiavuta (CIVEN) for skillful assistance in the AFM characterization.

\section{References}

[1] B. K. Mandal, K. T. Suzuki, Talanta 2002, 58, 201.

[2] W. Holak, Anal. Chem. 1969, 41, 1712.

[3] M. Belli, D. Centioli, P. d. Zorzi, U. Sansone, S. Capri, R. Pagnotta, M. Pettine, Vol. Metodi Analitici per le Acque, APAT \& IRSA-CNR, Roma 2004, p. 3080.

[4] K. J. Stetzenbach, M. Amano, D. K. Kreamer, V. F. Hodge, Ground Water 1994, 32, 976.

[5] E. H. Larsen, G. Pritzl, S. H. Hansen, J. Anal. At. Spectrom. 1993, 8, 1075.

[6] B. S. Sheppard, W. L. Shen, J. A. Caruso, D. T. Heitkemper, F. L. Fricke, J. Anal. At. Spectrom. 1990, 5, 431.

[7] L. Meiters, J. Am. Chem. Soc. 1954, 76, 5927.

[8] U. Greulach, G. Henze, Anal. Chim. Acta 1995, 306, 217.

[9] A. Profumo, D. Merli, M. Pesavento, Anal. Chim. Acta 2005, 539, 245.

[10] I. Svancara, K. Vytras, A. Bobrowsky, K. Kalcher, Talanta 2002, 58,45 . 
[11] X. Dai, O. Nekrassova, M. E. Hyde, R. G. Compton, Anal. Chem. 2004, 76, 5924.

[12] R. Feeney, S. P. Kounaves, Anal. Chem. 2000, 72, 2222.

[13] M. Khairy, D. K. Kampouris, R. O. Kadara, C. E. Banks, Electroanalysis 2010, 22, 2496.

[14] M. Hossain, M. Islam, S. Fersousi, T. Okajiama, T. Ohsaka, Electroanalysis 2008, 20, 2435.

[15] X. Dai, R. G. Compton, Anal. Sci. 2006, 22, 567.

[16] L. Vega, M. Styblo, R. Petterson, W. Cullen, C. Wang, D. Germolec, Toxicol. Appl. Pharmacol. 2001, 172, 225.

[17] F. C. Bodewig, P. Valenta, H. W. Nurnberg, Fresenius $Z$. Anal. Chem. 1982, 311, 187.

[18] H. Huang, P. K. Dasgupta, Anal. Chim. Acta 1999, 380, 27.

[19] C. M. Barra, M. M. Correia dos Santos, Electroanalysis 2001, 13, 1098.

[20] R. Feeney, S. P. Kounaves, Talanta 2002, 58, 23.

[21] P. H. Davis, G. R. Dulude, R. M. Griffin, W. R. Matson, E. W. Zink, Anal. Chem. 1978, 50, 137.

[22] S. W. Lee, J. C. Miranger, Anal. Chem. 1981, 53, 130.

[23] R. I. Mrzljak, A. M. Bond, T. J. Cardwell, R. W. Cattrall, O. M. G. Newmann, B. R. Champion, Analyst 1994, 119, 1051.

[24] P. Ugo, L. M. Moretto, F. Vezzà, ChemPhysChem 2002, 3, 917.

[25] V. P. Menon, C. R. Martin, Anal. Chem. 1995, 67, 1920.

[26] B. Brunetti, P. Ugo, L. M. Moretto, C. R. Martin, J. Electroanal. Chem. 2000, 491, 166.

[27] S. Viswanathan, W.-C. Liao, C.-C. Huang, W.-L. Hsu, J. A. Ho, Talanta 2007, 74, 229.

[28] P. Ugo, N. Pepe, L. M. Moretto, M. Battagliarin, J. Electroanal. Chem. 2003, $560,51$.
[29] S. P. Mucelli, M. Zamuner, M. Tormen, G. Stanta, P. Ugo, Biosens. Bioelectron. 2008, 23, 1900.

[30] L. Cao, P. Yan, K. Sun, D. W. Kirk, Electroanalysis 2009, 21, 1183.

[31] F. C. Pereira, L. M. Moretto, M. D. Leo, M. V. B. Zanoni, P. Ugo, Anal. Chim. Acta 2006, 575, 16.

[32] P. Ugo, L. M. Moretto, M. Silvestrini, F. C. Pereira, Intern. J. Environ. Anal. Chem. 2010, 90, 747.

[33] B. K. Jena, C. R. Ray, Anal. Chem. 2008, 80, 4836.

[34] L. M. Moretto, N. Pepe, P. Ugo, Talanta 2003, 62, 1055.

[35] M. D. Leo, F. C. Pereira, L. M. Moretto, P. Scopece, S. Polizzi, P. Ugo, Chem. Mater 2007, 19, 5955.

[36] P. Ugo, L. M. Moretto, Handbook of Electrochemistry (Ed: C. Zoski), Elsevier, Amsterdam 2007, ch. 16.2.

[37] M. Silvestrini, P. Schiavuta, P. Scopece, G. Pecchielan, L. M. Moretto, P. Ugo, Electrochim. Acta 2011, 56, 7718.

[38] Y.-C. Sun, J. Mierzwa, M.-H. Yang, Talanta 1997, 44, 1379.

[39] G. Dugo, L. L. Pera, V. L. Turco, G. D. Bella, Chemosphere 2005, 61, 1093.

[40] M. Kopanica, L. Novotny, Anal. Chim. Acta 1998, 368, 211.

[41] R. S. Sadana, Anal. Chem. 1983, 55, 304.

[42] H. Li, R. B. Smart, Anal. Chim. Acta 1996, 325, 25.

[43] M. D. Leo, A. Kuhn, P. Ugo, Electroanalysis 2007, 19, 227.

[44] R. Greef, R. Peat, L. M. Peter, D. Pletcher, J. Robinson, in Instrumental Methods in Electrochemistry, Ellis Horwood, Chichester 1985, ch. 6.

[45] K. Brainina, E. Neyman, in Electroanalytical Stripping Methods, Wiley, New York 1993, Ch. 1 and 2.

[46] X. Dai, R. G. Compton, Electroanalysis 2005, 17, 1325. 